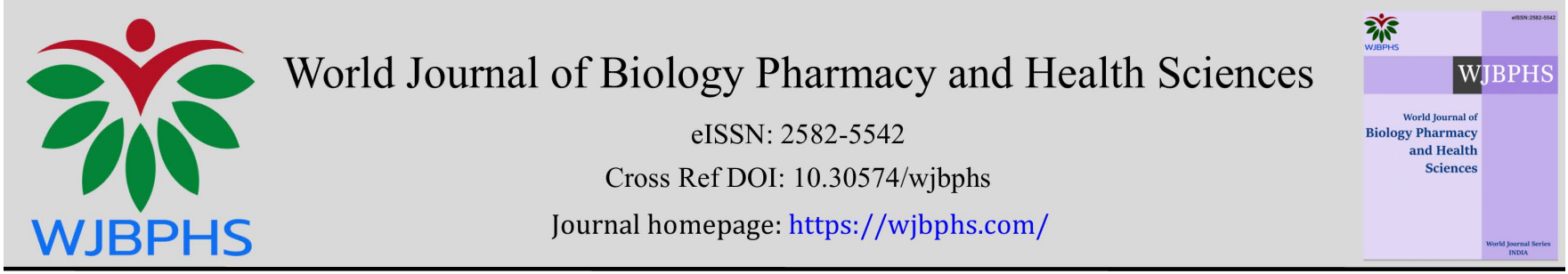

(RESEARCH ARTiCle)

\title{
Assessment on the effect of selected oral contraceptives on the liver functionality and integrity
}

\author{
Tamuno-Boma Odinga 1,*, Barizoge Cletus Lemii 2, Ransome Iyaeneomi Daka ${ }^{2}$ and Sarah Kelechi Enebeli ${ }^{3}$ \\ ${ }^{1}$ Department of Biochemistry, Faculty of Science, Rivers State University, Nigeria. \\ 2 Department of Pharmacology and Therapeutics, Faculty of Basic Clinical Sciences, Rivers State University, Nigeria. \\ ${ }^{3}$ Department of pharmacology, faculty of basic clinical sciences, college of medical sciences, Rivers State University, Nigeria.
}

World Journal of Biology Pharmacy and Health Sciences, 2022, 09(02), 046-054

Publication history: Received on 07 January 2022; revised on 14 February 2022; accepted on 16 February 2022

Article DOI: https://doi.org/10.30574/wjbphs.2022.9.2.0037

\begin{abstract}
Oral contraceptives have been useful in birth control and other gynecological disorders; it is sometimes abused due to ignorance and other underlying factors. The liver is saddled with the responsibility of drug metabolism. This study assessed the effect of oral contraceptives on the liver functionality and integrity. A total of 25 female albino rats were obtained and allowed to acclimatize in the animal house of the department of Pharmacology, Rivers State University for 7 days. The rats were divided into five groups of five animals in each group. Group 1 served as control, Group 2 and 3 were administered with low and high doses of Exluton, while group 4 and 5 were administered low and high doses of Combination-3 respectively. The albino rats in all groups were allowed feed and water ad libitum. The experimental process lasted for 21 days, after which the animals were sacrificed, blood samples collected into sterile bottles for biochemical assay using standard laboratory procedures, while the liver was harvest for histological examination. The results obtained from analysis revealed a slight insignificant increase in the concentration of serum AST when administered Exluton and Combination-3 at both doses. ALP serum concentration reduced at all doses of the drugs administered, while ALT had an inconsistent variation. Total protein and ALB decreased in concentration while Bilirubin had an increased serum concentration. This study suggests impairment on the functionality and the integrity of the liver on administration of Oral contraceptives over a long period, dose dependent and a possible distortion in platelet function. The biliary system of the liver however may not be altered.
\end{abstract}

Keywords: Liver functionality; Exluton; Combination-3; Oral Contraceptive pills; Liver integrity; Liver biomarkers

\section{Introduction}

Combined oral contraceptive pills are a type of oral medication that is designed to be taken every day, at the same time of day, in order to prevent pregnancy [1]. There are many different formulations or brands, but the average pack is designed to be taken over a 28-day period, or cycle. If used exactly as instructed, the estimated risk of getting pregnant is $0.3 \%$, or about 3 in 1000 women on combined oral contraceptive pills (COCPs) will become pregnant within one year [2]. However, typical use is often not exact due to timing errors, forgotten pills, or unwanted side effects. With typical use, the estimated risk of getting pregnant is about $9 \%$, or about 9 in 100 women on COCP will become pregnant in one year [3].

Lynestrenol, sold under the brand name Exluton is a progestin medication which is used in birth control pills and in the treatment of gynecological disorders [4,5,6]. Exluton is a brand of progesterone only pill containing specifically 500 mirogram of lynestenol in each tablet. It is mainly used when COCPs are contraindicated like during breast feeding and serves to prevent pregnancy.

\footnotetext{
${ }^{*}$ Corresponding author Tamuno-Boma Odinga

Department of Biochemistry, Faculty of Science, Rivers State University, Nigeria.

Copyright $(2022$ Author(s) retain the copyright of this article. This article is published under the terms of the Creative Commons Attribution Liscense 4.0.
} 
Combination-3 oral contraceptive is a combination of an estrogen (usually ethinylestradiol) and a progestogen (specifically a progestin). It is used to avoid pregnancy when taken within 72 hours of having unprotected sex, Prevention of pregnancy, reduces or stops the short-term changes of menopause, Hormonal contraceptive, treatment of Iron deficiency anemia, use in dysfunctional uterine bleeding, treatment of failure of ovarian development and other conditions. Combination 3 Tablet contains Ethinylestradiol, Fumarate and Levonorgestrel as active ingredients and works by stopping ovaries from releasing an egg; inhibiting the ovulation; producing blood cells and platelets in the body [7].

Oral contraceptives hormonal pills act by thickening the female cervical mucus, altering hormone balance and by decreasing endometrial oocyte receptivity thus preventing sperm penetration, fertilization and implantation [8]. Studies have reported high degree of misuse of oral contraceptives among Jordanian males mainly for body building [9].In a research [2], conducted by WHO, it was found that Oral hormonal contraceptive pills are more than $99 \%$ effective in preventing fertilization if consumed the right way.

Despite its effectiveness, some side effects have been reported. Adverse effects associated with the use of oral contraceptives include nausea, breast tenderness, inter-menstrual bleeding, amenorrhea, and headaches has been also reported [10].These substances can act directly or indirectly on the liver to produce a variety of biological effects which have both physiological and pathological significance [11]. A research on the Synergistic Ingestion of Tramadol, Calabash Chalk (Nzu), Cigarette, Alcohol and Codeine: It's Impact on the Renal and Hepatic Function of Male Humans observed that the abuse/intake of drugs/medication in doses not prescribed can alter the integrity of the hepatic cells [12]. Research has also shown that women who use contraceptive drugs are prone to cervical cancer. Hence, there is need to assess the effect of the drugs (Exulton and Combination 3) used as contraceptive drugs on the liver biomarker.

The liver plays a significant role in the metabolism of both endogenously produced hormones and synthetic or exogenous hormones in clinical setting. Considering the role of liver in metabolism of drugs, it is expedient to evaluate the effect the administration of oral contraceptive may exert on the liver function using the enzymatic and nonenzymatic liver biomarkers as well as on liver histology.

\section{Material and methods}

\subsection{Experimental animals}

Twenty-five adult female albino rats were obtained from the Animal house of Rivers State University, Port Harcourt and taken to the experimental laboratory where they were divided into 5 groups of five albino rats each. They were allowed standard feed and water ad libitum and allowed to acclimatize for 7 days.

\subsection{Drug of study}

Exluton is a brand of progesterone only pill containing specifically 500mirogram of lynestenol in each tablet. A combination 3 pills is a COCP containing levonorgestrel $0.15 \mathrm{mg}$ and ethinylestradiol $0.03 \mathrm{mg}$ and iron based compound, iron fumarate. Both drugs were purchased from a Medical Pharmacy in Port Harcourt, Rivers State, Nigeria. The Combination 3 tablet used consists of 21 hormonal tablets and 7 non-hormonal tablets. Each white hormonal tablet contains low doses of estrogen and progesterone hormones.

\subsection{Experimental grouping/drug administration}

The female albino rats were divided into five groups:

- $\quad$ Group 1: Feed + Water only

- Group 2: Low dose Exluton + feed + water

- Group 3: High dose Exluton + Feed + Water

- Group 4: Low dose Combination $3+$ Feed + Water

- Group 5: High dose Combination 3+ Feed + Water

Administration of drugs were as reported [11], Each day a tablet is dissolved in $100 \mathrm{~mL}$ distilled water and the appropriate dose per kg was measured out using a $2 \mathrm{~mL}$ syringe for oral administration via an oro-gastric tube. Low dose received $0.14 \mathrm{~mL}$ while high dose received $0.30 \mathrm{~mL}$ of the prepared drug. These doses were determined based on comparative dosage per body weight proportion akin to humans. 


\subsection{Sample collection}

Twenty-four hours after the last administration, the albino rats were sacrificed, blood samples were collected from each of the rats into sterile sample bottles for analysis of the liver functionality and integrity. The liver of each albino rat was harvested for Histological examination.

\subsection{Sample analysis}

Liver functionality was evaluated using the by the serum concentration of total protein, total and conjugated bilirubin and these were assayed as described [13] for total protein and [14] for bilirubin contents.

Serum aspartate amino transferase (AST) and alanine amino transferase (ALT) activities were estimated for liver integrity using Randox reagent kit using 2, 4-dinitrophenylhydrazine substrate [15].

Alkaline phosphatase (ALP) activity was determined for billary integrity with the Randox reagent kit using the pnitrophenylphosphate substrate as described [16].

\subsection{Data analysis}

The Mean \pm Standard deviation was determined and one-way analysis of variance were performed using SPSS version 25 software, thereafter; the Turkey Post Hoc was done for multiple comparison. The significance level was set at $\mathrm{p}<0.05$

\section{Results}

Table 1 Effect of exluton and combination 3 contraceptives on the liver and billary intergrity enzymatic biomarkers

\begin{tabular}{|l|l|l|l|}
\hline GROUP & AST (U/L) & ALT (U/L) & ALP(U/L) \\
\hline Control & $44.500 \mathrm{a} \pm 2.6458$ & $14.1250 \mathrm{a} \pm 3.8012$ & $45.2500 \mathrm{a} \pm 5.4391$ \\
\hline LD Exluton & $48.2500 \mathrm{a} \pm 4.0311$ & $15.5500 \mathrm{a} \pm 0.4435$ & $35.2500 \mathrm{a} \pm 7.9320$ \\
\hline HD Exluton & $50.5000 \mathrm{a} \pm 5.5678$ & $13.9400 \mathrm{a} \pm 3.0772$ & $37.2500 \mathrm{a} \pm 11.9826$ \\
\hline LD Combi3 & $54.8000 \mathrm{~b} \pm 6.0166$ & $13.9400 \mathrm{a} \pm 0.9864$ & $30.0000 \mathrm{a} \pm 9.4074$ \\
\hline HD Combi3 & $44.5000 \mathrm{a} \pm 3.1091$ & $14.9000 \mathrm{a} \pm 0.7071$ & $22.5000 \mathrm{~b} \pm 2.0817$ \\
\hline
\end{tabular}

AST: Aspartate-amino transferase, ALT: Alanine-amino transferase, ALP: Alkaline phosphatase; Values are Mean \pm Standard deviation and values within each liver and biliary integrity parameters having different superscript are statistically significant at $p<0.05$; values within each liver and biliary integrity parameters having the same superscript are not statistically significant at $\mathrm{p}<0.05$

Table 2 Effect of exluton and combination 3 contraceptives on the liver functional non-enzymatic biomarkers

\begin{tabular}{|l|l|l|l|l|}
\hline GROUP & TP(g/dl) & ALB(mg/dl) & TB(mg/dl) & CB (mg/dl) \\
\hline Control & $79.000 \mathrm{a} \pm 4.3205$ & $45.7500 \mathrm{a} \pm 2.2174$ & $8.8750 \mathrm{a} \pm 0.5058$ & $6.1750 \mathrm{a} \pm 0.3403$ \\
\hline LD Exluton & $75.7500 \mathrm{a} \pm 8.0571$ & $44.5000 \mathrm{a} \pm 4.2174$ & $10.0500 \mathrm{a} \pm 0.8813$ & $6.6500 \mathrm{a} \pm 1.5111$ \\
\hline HD Exluton & $71.0000 \mathrm{a} \pm 9.7639$ & $43.2500 \mathrm{a} \pm 4.7871$ & $10.5000 \mathrm{a} \pm 1.3589$ & $6.4500 \mathrm{a} \pm 1.2923$ \\
\hline LD Combi3 & $75.6000 \mathrm{a} \pm 9.4499$ & $44.0000 \mathrm{a} \pm 3.7417$ & $11.2400 \mathrm{~b} \pm 1.2582$ & $7.8800 \mathrm{a} \pm 1.3864$ \\
\hline HD Combi3 & $79.2500 \mathrm{a} \pm 6.4485$ & $45.0000 \mathrm{a} \pm 2.9439$ & $8.8500 \mathrm{a} \pm 0.6557$ & $6.0250 \mathrm{a} \pm 0.5124$ \\
\hline
\end{tabular}

TP: Total protein; ALB: Albumin; TB; Total bilirubin; CB: Conjugated bilirubin; Values are Mean \pm Standard deviation and values within each liver and biliary integrity parameters having different superscript are statistically significant at $\mathrm{p}<0.05$; values within each liver and biliary integrity parameters having the same superscript are not statistically significant at $\mathrm{p}<0.05$.

Result from Table 1 revealed that the concentration of blood AST increased in the albino rats administered Low dose and high dose of the contraceptive Exluton, when compared with the control group. However, the increase in variation was not statistically significant at P value 0.05 . An increase was also observed in the Serum AST level when albino rats were administered LD of Combination 3 , the increase was statistically significant at 0.05 level, while no variation was observed in the HD Combination 3 in the albino rats when compared to the control group. 
The result as shown on table 2 for the liver functional non-enzymatic biomarkers revealed that for Total protein, the administration of the low and high doses of Exluton reduced the serum TP level, same was observed for LD Combination 3 when compared to the control group. However, the administration of High dose of Combination 3 increased the TP level of the serum, although, the increase was not statistically significant at $\mathrm{P}$ value 0.05 in comparison to the control group. The serum concentration of Albumin when administered LD and HD Exluton reduced, as well as the LD and HD of the Combination 3 which reduced when compared to the control group. The reduction was not significant at $\mathrm{p}<0.05$ level. The serum concentration of TB in the female albino rats administered LD and HD of Exluton increased in comparison to the control group. The low dose of Combination 3 also increased the serum TB concentration. The increase in the concentration of ALB when administered LD Combination 3 was statistically significant at $p<0.05$ when compared to the control group, while the HD Combination 3 reduced the serum ALB. The same trend as TB was also observed for CB in the serum of female Albino rats. However, the varying increase and decrease in the serum CB were not statistically significant at $\mathrm{p}<0.05$ when compared to the control group.

\subsection{Histological Examination}

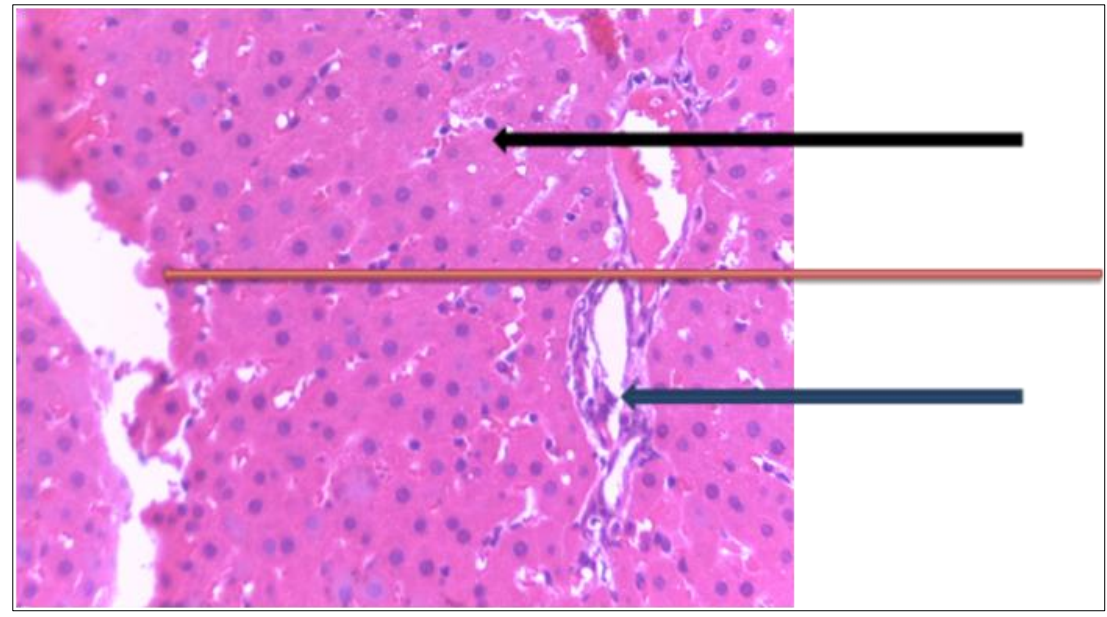

Figure 1 Section of the liver (Control) shows normal portal tract (blue), normal hepatocytes (black) and normal central veins (red)

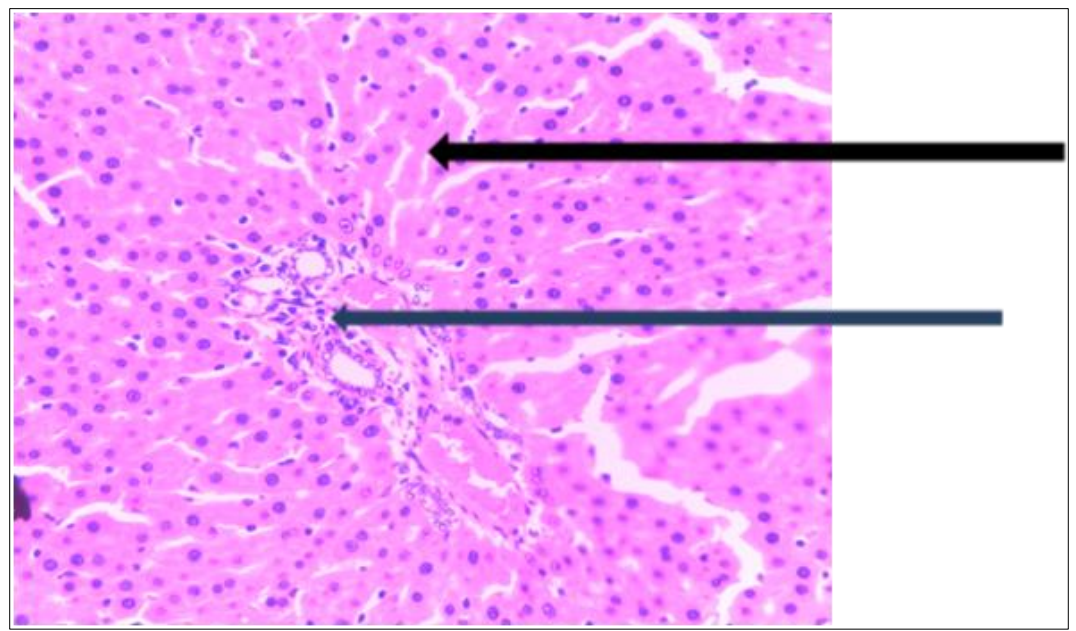

Figure 2 Section of the liver (LD Exluton) shows mild lymphocytic infiltration of the portal tract (blue) and normal hepatocytes (black) 


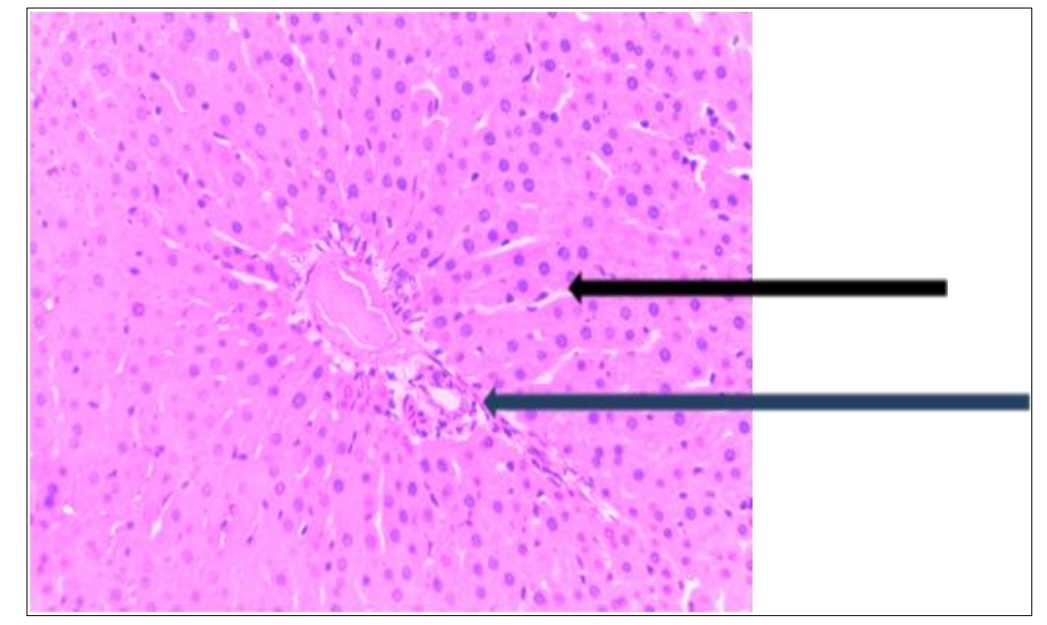

Figure 3 Section of the liver (HD Exluton) shows mild lymphocytic infiltration of the portal tract (blue) and normal hepatocytes (black)

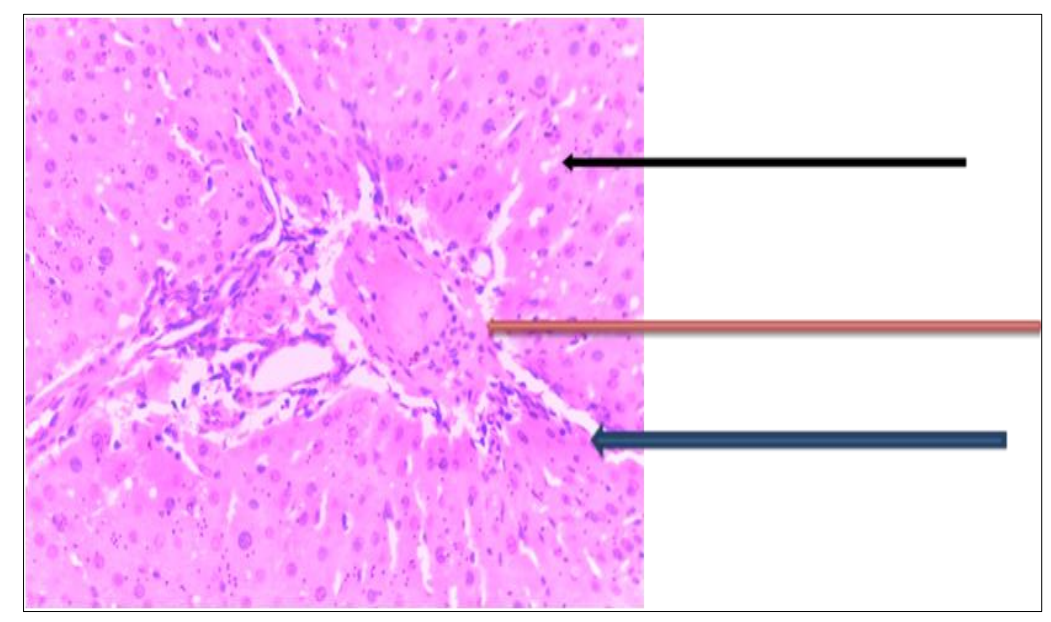

Figure 4 Section of the liver (HD Exluton) shows mild lymphocytic infiltration of the portal tract (blue) with congested portal tracts (red) and normal hepatocytes (black)

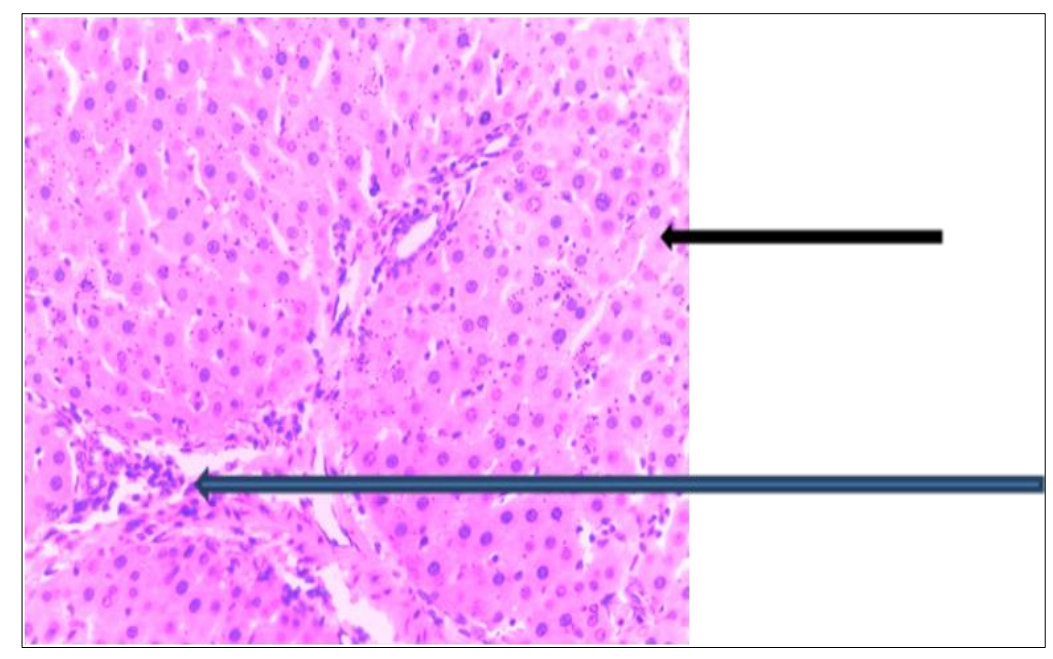

Figure 5 Section of the liver (LD Combination 3) shows mild lymphocytic infiltration of the portal tract (blue) and normal hepatocytes (black) 


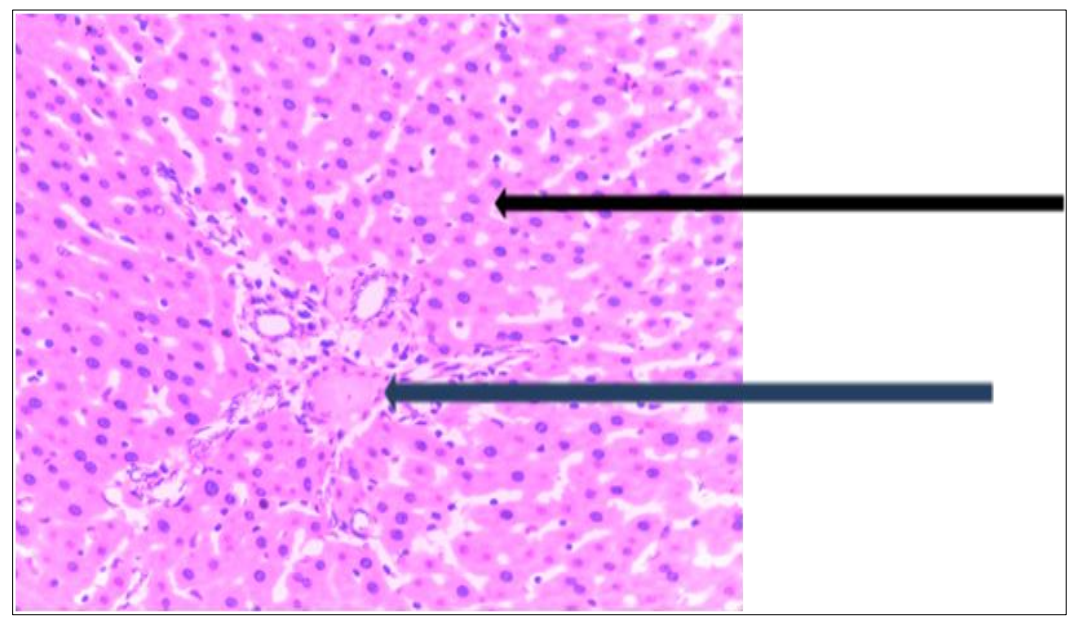

Figure 6 Section of the liver (LD Combination 3) shows mild lymphocytic infiltration of the portal tract (blue) and normal hepatocytes (black)

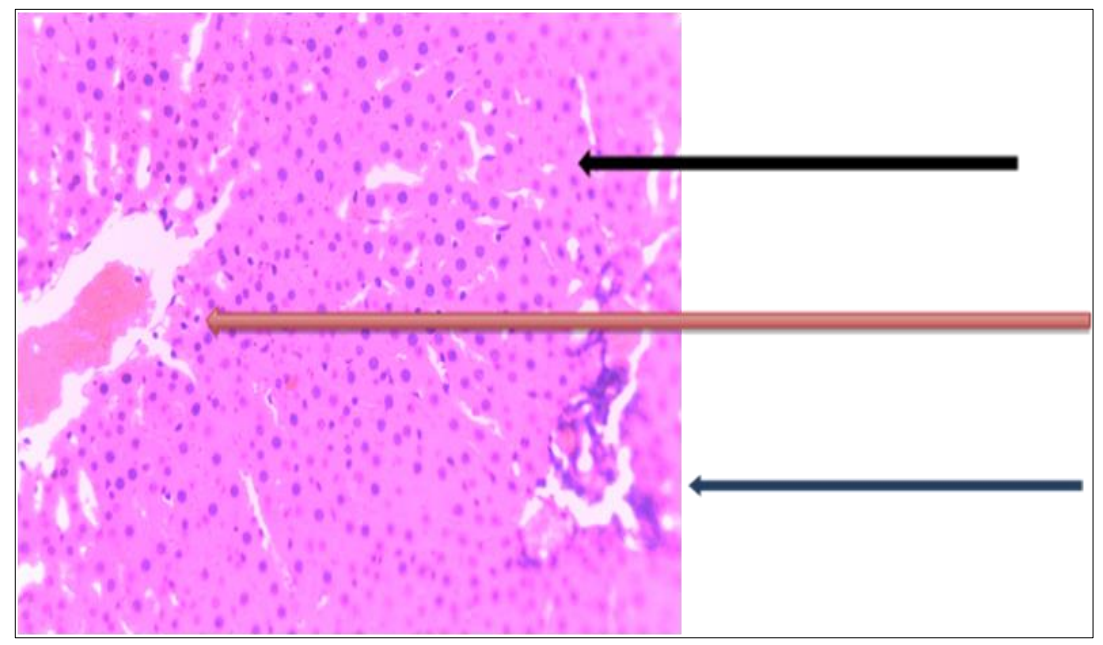

Figure 7 Section of the liver (LD Exluton) shows normal portal tract (blue), normal hepatocytes (black) and congested central veins (red)

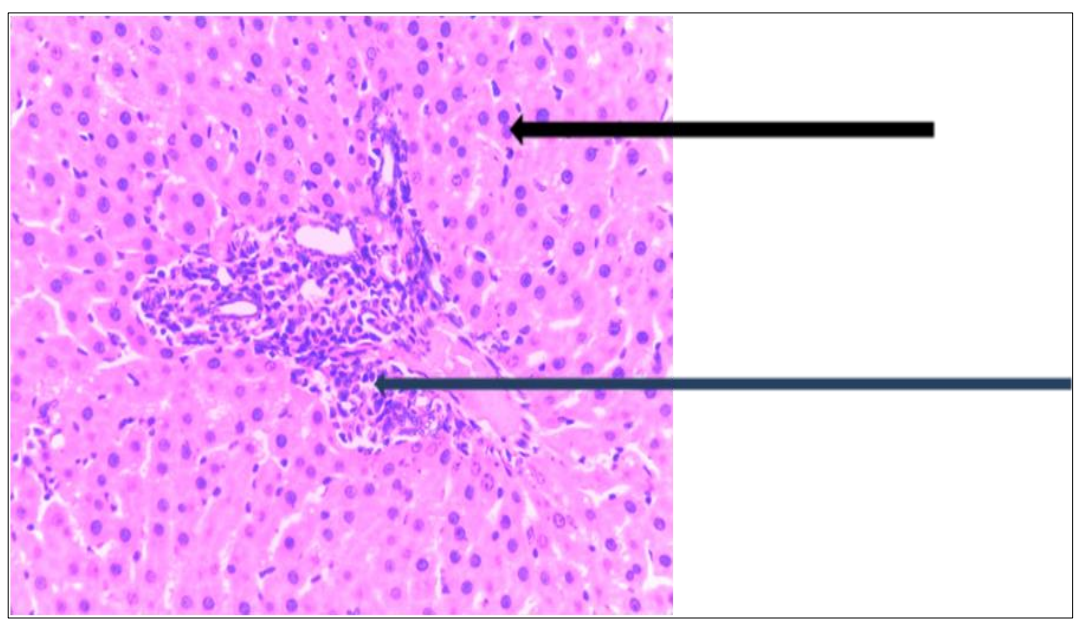

Figure 8 Section of the liver (HD Combination 3) shows marked lymphocytic infiltration of the portal tract (blue) and normal hepatocytes (black) 


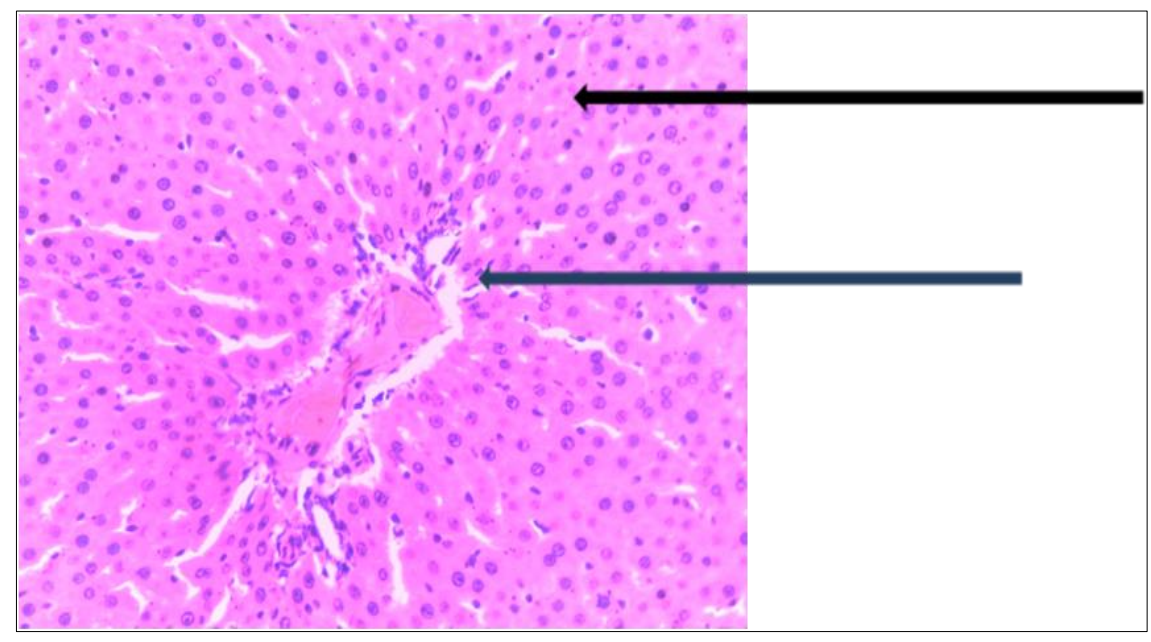

Figure 9 Section of the liver (HD Combination 3) shows mild lymphocytic infiltration of the portal tract (blue) and normal hepatocytes (black)

\section{Discussion}

The result on the effect of Exluton and Combination-3 on liver functionality is indicated via the concentrations of total protein, albumin, total bilirubin and Conjugated bilirubin. The result as shown in table 2 revealed that administration of low and high doses of both exluton and combination 3 reduced the serum concentration of Total protein and Albumin. Reduction in the serum concentration of Total protein and Albumin may be an indication of liver dysfunction [17, 18, 19]. A great percentage of bilirubin as reported [20,21] is made from the breakdown of hemoglobin in senescent red blood cells, and prematurely destroyed erythroid cells in the bone marrow. The findings of this study shows an increase in Total bilirubin and conjugated bilirubin in all doses administered, except in High Dose of Combination-3. The liver functions in filtration, storage and metabolism of blood and in the formation and excretion of bile [22]. It has been observed that OCP containing lower doses of synthetic hormones is similar to older OCPs which contains higher doses of synthetic hormones and by implication is hepatotoxic [23]. These reports are in consonance with the findings of this present study, hence a possible alteration in the functionality of the liver. This is further supported by the adverse effects observed via intake of Oral contraceptives, which includes breakthrough bleeding and amenorrhea as previously noted [23]. An adverse effect of low serum albumin is that drugs that are usually protein bound are free in the plasma, allowing for higher drug levels, more rapid hepatic metabolism, or both [11]. Alterations in albumin level affect platelet function [24]. In line with this report, the findings of this study suggest that administration of Exluton and Combination 3 at doses not prescribed may alter the platelet function of the body. This is evident in some of the adverse effects of intake of OCPs which includes breakthrough bleeding and amenorrhea [23].

The results for the integrity of the liver and billary is evidenced via the concentrations of theenzymatic biomarkers of the liver; AST, ALT and ALP. The serum concentrations were all seen to increase significantly for AST when compared to the control group. A decrease in the concentration of ALT was observed when administered HD Exluton and LD Combination-3. An increase in the serum concentration of AST and ALT may indicate hepatotoxicity [25, 26 27]. In view of their report, the findings of this study may suggest an impaired integrity of the liver, evidenced by the increase in AST and ALT. The concentration of serum ALP in the albino rats administered low and high doses of the drugs was observed to reduce significantly when compared to the control group. This suggests that the integrity of the biliary system may not be altered, despite the alteration in the functionality and integrity of the liver.

The histological examination of the liver further revealed mild lymphocytic infiltration of the portal tract in the liver of rats administered High dose combination 3, High dose Exluton and Low dose combination 3, while Congested central vein was observed in animals administered Low dose Exluton. This agrees with the findings that OCPs alters the integrity and functionality of the liver.

\section{Conclusion}

The use of Oral contraceptives, although has been of great health benefit, however, its abuse and misuse, mostly in doses not prescribed over a long period of time may alter the integrity and functionality of the liver, hence its toxicity. However, the biliary system of the liver may be in tact at all doses. 


\section{Compliance with ethical standards}

\section{Acknowledgments}

The authors wish to acknowledge the efforts of Miss Rita Olofu and Mr. Barine towards the completion of this study.

\section{Disclosure of conflict of interest}

All authors declare that they have no conflicts of interest.

\section{Statement of ethical approval}

All animals were handled in accordance with the Guide for the care and use of laboratory Animals prepared by the National Academy of Sciences and published by the National Institute of Health Guide for the use of Laboratory Animal.

\section{References}

[1] Callahan TL, Caughey AB. Blueprints obstetrics \& gynecology (6th ed.). Baltimore, MD: Lippincott Williams \& Wilkins. 2013.

[2] WHO. Medical Eligibility Criteria for Contraceptive Use. 4th Edn., World Health Organization, USA. 2010.

[3] Curtis KM, Tepper NK, Jatlaoui TC, Berry-Bibee E, Horton LG, Zapata LB, Simmons KB, Pagano HP, Jamieson DJ, Whiteman MK. "U.S. Medical Eligibility Criteria for Contraceptive Use, 2016". MMWR. Recommendations and Reports. July 2016; 65(3): 1-103.

[4] Elks J. The Dictionary of Drugs: Chemical Data: Chemical Data, Structures and Bibliographies. Springer. 2014; 747.

[5] Index Nominum: International Drug Directory. Taylor \& Francis. 2000; 624.

[6] Morton IK, Judith M, Hall Concise Dictionary of Pharmacological Agents: Properties and Synonyms. Springer Science \& Business Media. 2012; 170.

[7] Cooper DB, Mahdy H. Oral contraceptive pills.[Updated 2021 Aug 25]. StatPearls.

[8] Barakat M, Al-Qudah RA, Akour A, Abu-Asal M, Thiab S, Dallal Bashi YH. Knowledge and beliefs about the use/abuse of oral contraceptive pills among males: A mixed-method explanatory sequential study in community pharmacy settings. Plos one. 2021; 16(5): e0251302.

[9] Ekhato CN, Osifo UC and Akpamu U: Effect of Oral Contraceptive Pills (Containing Low Doses of Synthetic Hormones) on Liver Function in Adult Female Rabbits. Asian Journal of Biotechnology. 2014; 6: 15-20.

[10] Odinga T, Gabriel-Brisibe CU, Opusunju BH, Okwakpam FN, Azonwu 0, Orji KO. Synergistic Ingestion of Tramadol, Calabash Chalk (Nzu), Cigarette, Alcohol and Codeine: It's Impact on the Renal and Hepat-ic Function of Male Humans. Journal of Medicinal Chemistry and Toxicology. 2020; 4(1): 1-5.

[11] Tietz NW. Specimen Collection and Processing: Sources of Biological Variation in Textbook of Clinical Chemistry. 2nd Edn., W.B. Saunders, Philadelphia. 1994.

[12] Tietz NW. Clinical Guide to Laboratory Tests. 3rd Edn. W.B. Sauders, Philadelphia, USA. 1995.

[13] Reitman S, S Frankel. A colorimetric method for the determination of serum glutamic oxalacetic and glutamic pyruvic transaminases. Am. J. Clin. Pathol. 1957; 28: 56-63.

[14] Bessey OA, Lowry OH, Brock MJ. A method for the rapid determination of alkaline phosphates with five cubic millimeters of serum. J. Biol. Chem. 1946; 164: 321-329.

[15] Gatta A, Verardo A, Bolognesi M. Hypoalbuminemia. Intern Emerg Med. Oct 2012; 7(3): S193-9.

[16] Ballmer PE. Causes and mechanisms of hypoalbuminaemia. Clin Nutr. Jun 2001; 20(3): 271-3.

[17] Brock F, Bettinelli LA, Dobner T, Stobbe JC, Pomatti G, Telles CT. Prevalence of hypoalbuminemia and nutritional issues in hospitalized elders. Rev Lat Am Enfermagem. 8 Aug 2016; 24: e2736.

[18] Shen H, Zeng C, Wu X, Liu S, Chen X. Prognostic value of total bilirubin in patients with acute myocardial infarction: A meta-analysis. Medicine (Baltimore). 2019; 98(3): e13920. 
[19] Hinds TD, Stec DE. Bilirubin, a Cardiometabolic Signaling Molecule. Hypertension. 2018; 72(4): 788-795.

[20] Guyton AC, JC Hall. Text Book of Medical Physiology. W.B. Sanders Company, Philadelphia. 2006; 966-971.

[21] Serfaty D. Medical aspects of oral contraceptive discontinuation. Adv. Contracept. 1992; 8: 21-33.

[22] Peralta, R. Hypoalbuminemia. 2020.

[23] Ribeiro AJS, Yang X, Patel V, Madabushi R, Strauss DG. Liver Microphysiological Systems for Predicting and Evaluating Drug Effects. Clin Pharmacol Ther. 2019; 106(1): 139-147.

[24] Vagvala SH, O'Connor SD. Imaging of abnormal liver function tests. Clin Liver Dis (Hoboken). 2018; 11(5): 128134.

[25] Wilkerson RG, Ogunbodede AC. Hypertensive Disorders of Pregnancy. Emerg Med Clin North Am. 2019; 37(2): 301-316. 